\title{
Meningioma after immunomodulation for multiple sclerosis
}

\author{
Meningioma após imunomodulação em esclerose múltipla \\ Rodrigo Gonçalves Kleinpaul Vieira, Thiago Cardoso Vale, Cristiane Franklin Rocha, Carolina Reis Araújo, \\ Marco Aurélio Lana-Peixoto on behalf of the Brazilian Committee for Treatment and Research in Multiple \\ Sclerosis (BCTRIMS)
}

The coexistence of multiple sclerosis (MS) and central nervous system (CNS) tumors has been reported in more than 30 cases in literature. Meningiomas have been rarely seen in MS patients and their occurrence has been observed during the course of immunomodulatory drugs such as interferon betala and beta- $1 \mathrm{~b}^{1-3}$. We report a case of a frontal meningioma in a patient with relapsing-remitting multiple sclerosis (RRMS) treated with interferon beta-1a for seven years followed by glatiramer acetate for three years.

\section{CASE REPORT}

A 39-year-old Brazilian black woman had a one-month history of diplopia followed by paresthesia and weakness in the left upper limb eight months later. The patient fully recovered from both episodes, but had additional bouts of vertigo and weakness of the right hand, paraparesis with sphincter impairment and left facial paralysis in monthly intervals. Brain MRI revealed T2-weighted hyperintense lesions in periventricular, deep white matter and subcortical regions. There was no evidence of an intracranial tumor. Spinal cord MRI showed two T2-weighted hyperintense lesions in the lateral portion of $\mathrm{C} 2-\mathrm{C} 3$ and $\mathrm{C} 7$ vertebral levels with no gadolinium enhancement. Cerebrospinal fluid examination revealed 9 white blood cells/dL, $24 \mathrm{mg} / \mathrm{dL}$ of proteins and an immunoglobulin $\mathrm{G}$ index of 0.92 . She was diagnosed as having RRMS and interferon beta-la (22 mg three times a week) was started. After seven years, the patient's immunomodulatory therapy was changed to glatiramer acetate due to increasing levels of serum liver enzymes. Three years later, a follow-up brain MRI showed a gadolinium-enhanced round lesion in the basal part of the left frontal lobe, with typical appearance of meningioma, in addition to characteristic demyelinating lesions as seen in MS (Figure). The patient's expanded disability status scale score was 1.0 and her Goldmann perimetry was unrevealing.

\section{DISCUSSION}

There is some controversy in the literature about the incidence of brain tumors in MS patients ${ }^{1-3}$. Our patient used interferon beta-la for seven years, when the immunomodulatory treatment was switched to glatiramer acetate. Glatiramer acetate has been found in association with breast cancer and cutaneous lymphoma, but not with a CNS neoplasm ${ }^{4,5}$. To the best of our knowledge, this is the first report that suggests the association of glatiramer acetate with a CNS tumor. The intracranial meningioma was asymptomatic and casually found in a routine follow-up brain MRI performed three years following the drug switch. Whether any of the immunomodulatory drugs had a role on the meningioma development or the CNS tumor occurred in this MS patient as a sheer coincidence phenomenon, remains to be clarified.

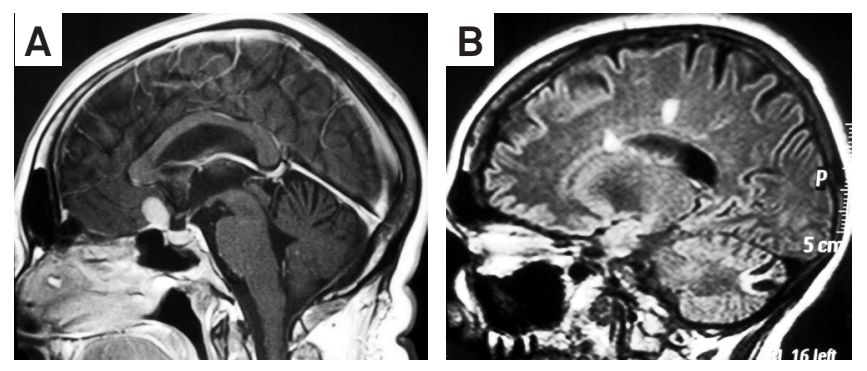

Figure. (A) Sagittal gadolinium-enhanced T1-weighted brain magnetic resonance imaging showing a homogenous enhanced round lesion in the base of the anterior skull. (B) Sagittal T1-weighted brain magnetic resonance imaging showing hyperintense lesions with typical multiple sclerosis appearance. 


\section{References}

1. Handel AE, Ramagopalan SV. Multiple sclerosis and risk of cancer: a meta-analysis. J Neurol Neurosurg Psychiatry 2010;81: 1413-1414.

2. Drevelegas A, Xinou E, Karacostas D, Parissis D, Karkavelas G, Milonas I. Meningioma growth and interferon beta-1b treated multiple sclerosis: coincidence or relationship? Neuroradiology 2005;47:516-519.

3. Gama HPP, Rocha AJ, Silva CJ, et al. Meningioma growth during interferon beta-1atreatmentformultiplesclerosis.Arq Neuropsiquiatr 2008;66:402-404

4. Amaria RN, Corboy JR, Finlayson CA, Robinson WA, Borges VF Immunomodulatory therapy in multiple sclerosis and breast cancer risk: a case report and literature review. Clin Breast Cancer 2008;8:449-452.

5. Madray MM, Greene JF Jr, Butler DF. Glatiramer acetate-associated, CD30+, primary, cutaneous, anaplastic large-cell lymphoma. Arch Neurol 2008;65:1378-1379. 